\title{
Glacial Modulation of Rapid Climate Change During the Last 0.5 Million Years
}

Two often competing priorities, the temporal length and resolution of paleoenvironmental records, may be simultaneously addressed using long cores from rapidly accumulating deep-sea sediment deposits. Site 980 of the Ocean Drilling Program's Leg 162 (Jansen et al., 1996) was drilled on the Feni Drift in the subpolar North Atlantic (Figure 2), and provides such an opportunity. The uppermost 65 meters of sediment at this site represent the last $0.5 \mathrm{myr}$, at an average accumulation rate of $13 \mathrm{~cm} / \mathrm{kyr}$, easily resolving millennial-scale features while encompassing more than four full glacial-interglacial (G-IG) climate cycles. This combination of length and resolution affords the possibility to evaluate short-term variability in the context of orbital-scale influence. Measurements of regional and global climate proxies from Site 980 reveal persistent patterns of variability, and suggest that the amplitudes of rapid oscillations are influenced by the baseline climate state, particularly the size of continental ice sheets.

Monticchio, continued from page 11

viding evidence for additional environmental fluctuations not seen in this part of the ice-core record. From this correlation with GISP2, as well as from correlations with high resolution ocean records such as that from DSDP-609, it is concluded that the Monticchio record clearly demonstrates a link between the closely coupled ocean-atmosphere system of the North Atlantic region and environmental changes in the Mediterranean region.

\section{Judy R.M. Allen}

GeoForschungszentrum Potsdam, Germany judy@gfz-potsdam.de

\section{Brian Huntley}

Environmental Research Centre, University of Durham, Durham, UK

brian.huntley@durham.ac.uk

Full references for this article can be found at www.pages.unibe.ch/ publications/newsletters/ref993.html
Stable oxygen isotope ratios $\left(\delta^{18} \mathrm{O}\right)$ in benthic and planktic foraminifera provide information about the degree of global glaciation and near-surface hydrography, respectively. The $\delta^{18} \mathrm{O}$ of the benthic species, $C$. wuellerstorfi, primarily reflects the global ice volume and the temperature of the deep ocean (Emiliani, 1955; Shackleton, 1967), while the $\delta^{18} \mathrm{O}$ of the planktic species, dextralcoiling $N$. pachyderma, bears the strong imprint of local hydrography, particularly sea-surface temperature (Keigwin and Jones, 1989; Oppo et al., 1997, 1998). Additional information about the surface ocean and the link to nearby icesheets comes from measurements of ice-rafted debris (IRD). Previous studies of the last G-IG cycle have demonstrated that sediments on Feni faithfully capture a signal of at least regional extent (Ruddiman et al., 1977; Duplessy et al., 1981; Broecker et al., 1988a,b; Bond et al., 1992; 1993; 1999; Lehmann and Keigwin, 1992; McManus et al., 1994; Labeyrie et al., 1995; Bond and Lotti, 1995).

Each of the three proxies varies in a different fashion (Figure 9), and each shares important links with the other two. The benthic $\delta^{18} \mathrm{O}$ displays the familiar sequence of glacial and interglacial Marine Isotope Stages (MIS) of the standard orbital chronostratigraphy (Emiliani, 1955; Imbrie et al., 1984; Martinson et al., 1987; Shackleton et al., 1990). By this measure, MIS 1, 5e, 9, and 11 are the most "interglacial" stages, with similarly low $\delta^{18} \mathrm{O}$ values. MIS 2, 6, and 10 have similarly high $\delta^{18} \mathrm{O}$ values, and are all surpassed by MIS 12, the most extreme glaciation of the last $0.5 \mathrm{Myr}$. The close agreement of these observations with those based on a compilation that emphasized benthic records from outside the North Atlantic (Shackleton, 1987) underscores the global significance and utility of benthic $\delta^{18} \mathrm{O}$. G-IG amplitudes of the benthic $\delta^{18} \mathrm{O}$ record at Site 980 are consistently larger $(>2.0 \%$ ) than those outside the region. These larger amplitudes, combined with the consistent relationships among respective glacial and interglacial extremes, indicate that not only did the deep North Atlantic experience a particularly large temperature change during the last G-IG cycle (Duplessy et al., 1980), but that it must have undergone equivalently large temperature changes relative to the global deep ocean during previous cycles.

IRD varies throughout the record, with a markedly episodic character that contrasts with the more smoothly varying benthic $\delta^{18} \mathrm{O}$. The youngest IRD episodes represent the catastrophic discharges that punctuated the last ice age (Heinrich, 1988; Broecker et al., 1992; Bond et al., 1992; cf review by Andrews, 1998), and comparable features occur throughout the record. Each glacial interval contains several IRD events, the last of which (McManus et al., 1994; Venz et al., 1999) is associated with the rapid deglaciation, or termination (Broecker, 1984) that marks the transition to the subsequent interglacial stage. IRD peaks are only associated with benthic $\delta^{18} \mathrm{O}$ values above approximately 3.5\% , suggesting a threshold for iceberg discharge.

The $\delta^{18} \mathrm{O}$ of dextral-coiling N. pachyderma displays large-amplitude variations, with several G-IG cycles of 3.0\% . Although such a range of values is remarkable, it is less than the equivalent range suggested by the broad temperature tolerance of this species (Be and Tolderlund, 1971; Kipp, 1976; Pflaumann et al., 1996), and by measurements of modern specimens (Figure 9). Only MIS 5e slightly surpasses MIS 1 as an interglacial extreme, and is approached by both MIS 9 and MIS 11. MIS11 is by far the longest interglacial, including a warm, IRD free interval of 30-40kyr. MIS 12 is the coldest glacial stage, as well as the most glaciated, followed by MIS 2, 6, and 10. Rapid oscillations of approximately $1.0 \%$ occur within the glacial stage of each large cycle, whereas peak interglacial variability is limited to less than $0.3 \%$. As with the IRD discharges, benthic $\delta^{18} \mathrm{O}$ values of approximately $3.5 \%$ mark the transition between more and less variable modes of millennial-scale variability. After correction for the ice volume effect on $\delta^{18} \mathrm{O}$ (Labeyrie et al., 1987; Fairbanks, 1989; Schrag, 1996), the planktic isotopic variations represent sea surface temperature (SST) changes of $8-9^{\circ} \mathrm{C}$ for each G-IG cycle. On shorter timescales, the SST 


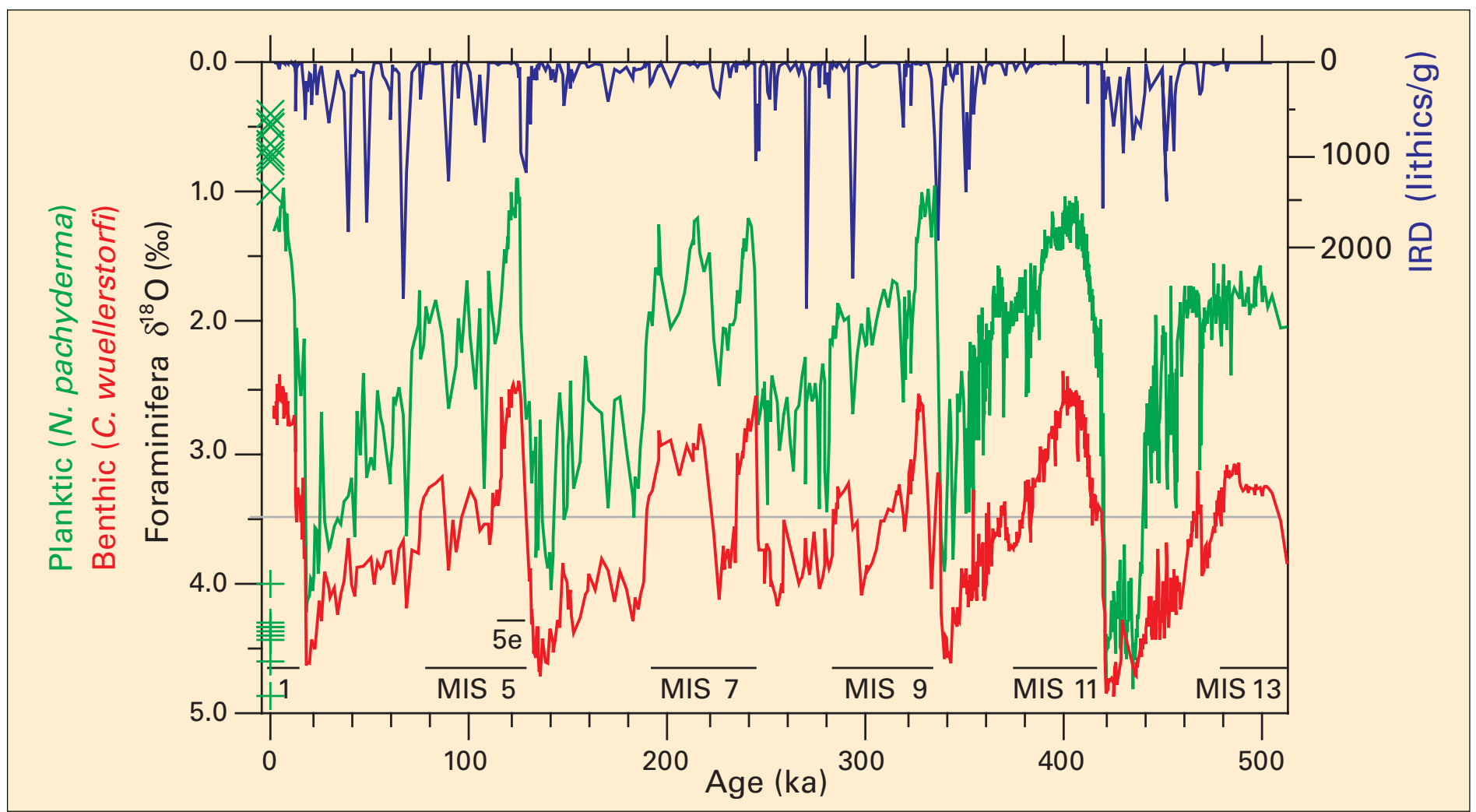

Figure 9: Oxygen isotope $\left(\delta^{18} O\right)$ and ice-rafted debris (IRD) measured in sediments from Site 980. IRD index is the number of detrital sediment grains (lithics), larger than $150 \mathrm{~mm}$, per bulk sample weight. Benthic (C. wuellerstorfi, red) and planktic (N. pachyderma d., green) foraminifera $\delta^{18} \mathrm{O}$ values are calculated relative to the Peedee Belemnite (PDB) standard (Emiliani, 1955), and plotted on the same scale. Data points at 0 kyr are $\delta^{18} \mathrm{O}$ measurements on modern $\mathrm{N}$. pachyderma d. from Atlantic sediment traps at $47^{\circ} \mathrm{N}(x)$ and $65^{\circ} \mathrm{N}(+)$, demonstrating an isotopic range surpassing that of our sedimentary data. The modern data from $65^{\circ} \mathrm{N}$ are adjusted by $+1.0 \%$, a minimum estimate of past mean ocean changes (Labeyrie et al., 1987; Fairbanks, 1989; Schrag et al., 1996), for comparison to glacial data. Interglacial marine isotope stages (MIS) and the last peak interglacial substage 5e are indicated for reference. All other intervals represent glacial stages (MIS 2-4, 6, 8, 10, 12). From McManus, J.F., Oppo, D.W., and Cullen, J.L., 1999, A 0.5 million year record of millennial-scale climate variability in the North Atlantic: Science, 283, 971-975.

changes are $1-2^{\circ} \mathrm{C}$ within the peak interglacial portion and $3-6^{\circ} \mathrm{C}$ within the glacial portion of each large climate cycle. The most extreme glacial interval, MIS 12 , does not have the highest degree of variability, but rather a series of $3^{\circ} \mathrm{C}$ oscillations. This pattern of climate response is similar to that observed during recent climate cycles in many records, including Greenland ice cores (e. g., Dansgaard and Oeschger, 1989; Johnsen et al., 1992; Grootes et al., 1993).

The benthic $\delta^{18} \mathrm{O}$ threshold for amplified variability occurs near the mid point of the range of values observed at Site 980 . However, because of the deep ocean temperature changes that are preferentially associated with peak interglacial intervals (Chappell and Shackleton, 1986; Labeyrie et al., 1987, Shackleton, 1987), the threshold value of $3.5 \%$ may represent as little as a $30 \mathrm{~m}$ departure from modern sea level. This threshold amount of glaciation modulates the higher-frequency climate response in the North Atlantic and probably beyond, as evidenced by similar records from outside the immediate region (e. g., Tzedakis et al., 1996). Throughout more than four large G-IG cycles, the pattern of climate variability is clear. The Site 980 record of the last 0.5 million years demonstrates that millennial-scale variability is persistent, with a regional, possibly global, amplitude that is modulated by the degree of global glaciation.

\section{Jerry McManus \& Delia Oppo}

Woods Hole Oceanographic Institution, USA jmcmanus@whoi.edu

doppo@whoi.edu

\section{James Cullen}

Salem State College, USA

cullen@dgl.ssc.mass.edu

Full references for this article can be found at www.pages.unibe.ch/ publications/newsletters/ref993.html

\section{$31^{\text {st }}$ International Geological Congress Travel Fellowships}

The $31^{\text {st }}$ International Geological Congress, August 6-17, Rio de Janeiro, Brazil, will have a number of sessions organized by, and of interest to PAGES scientists (see PAGES News Vol. 7 No. 2). The Geological Society of America has recently announced (EOS Vol 80 No. 42) fellowships for residents or citizens of the United States, born after August 31, 1960 for grants consisting of a roundtrip airfare to Brazil. Application forms are available from Grants Administrator, GSA Headquarters, 3300 Penrose Place, PO Box 9140, Boulder CO 80301, USA and are due postmarked no later than February 15.

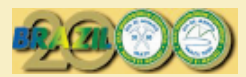

